\title{
Filosofia aberta, modelos de negócios e agências de fomento: elementos essenciais a uma discussão sobre o acesso aberto à informação científica
}

Sely M. S. Costa

$\mathrm{PhD}$ in Information Science, Loughborough

University, Inglaterra.

Universidade de Brasília/ Departamento de Ciência da Informação

E-mail: selmar@unb.br

\section{Resumo}

Com o objetivo de fomentar discussões a respeito da questão do acesso aberto à informação científica, o trabalho discorre sobre uma "filosofia aberta", a qual se refere ao movimento em direção ao uso de ferramentas, estratégias, metodologias e políticas que denotem um novo modelo de representar o processo de comunicação científica - especialmente no que concerne à publicação -, ao mesmo tempo em que serve de base para interpretá-lo. Esse novo modelo tem como fundamento a preocupação crescente com a disponibilidade, ao maior número possível de interessados, do conhecimento gerado como resultado tanto de pesquisas científicas (conhecimento científico) como da ação do homem na sociedade (herança cultural). O texto centra o foco nas questões relacionadas somente com o acesso aberto ao conhecimento científico. Nesse sentido, discorre sobre três questões: as principais iniciativas internacionais sobre acesso aberto; os novos modelos de negócios para o periódico científico, em resposta a essas iniciativas; e o papel que agências de fomento têm nesse contexto, com vistas a validar esses novos modelos. Introduz na discussão a questão das diferenças disciplinares, determinadas pelos padrões de comunicação das comunidades científicas, no que concerne à geração, disseminação e uso da informação. Conclui com uma análise breve dos impactos que o movimento em favor do acesso aberto provoca sobre os principais atores da comunicação científica, nomeadamente, universidades e seus pesquisadores, editores científicos e agências de fomento.

\section{Palavras-chave}

Acesso aberto. Filosofia aberta. Comunicação científica. Conhecimento científico. Modelos de negócios de editores científicos. Agências de fomento.

\section{Open philosophy, business models and funding agencies: essential elements for the discussion of open access to scientific information}

\begin{abstract}
In order to stimulate the discussion about open access to scientific information, this paper examines an open philosophy, which is related to the use of tools, strategies, methodologies and policies that points out a new way of depicting the scholarly communication process - particularly in terms of publishing - while providing a basis for its interpretation, as well. This new model is based on a growing concern about the availability of knowledge to a greater number of people interested in it. Such knowledge is created as a result of both scientific research (scientific knowledge) and the action of human beings on the society (cultural heritage). The text focuses solely on questions related to open access to scientific knowledge. In this regard, it deals with three issues: the major international initiatives on open access; new business models for scholarly and scientific journals as a response to these initiatives; the role performed by funding agencies in this context, aiming at the validation of these new models. It also introduces into the discussion the issue of disciplinary differences determined by communication patterns within scholarly communities concerning information production, dissemination and use. In conclusion, the paper presents a brief analysis of the impact that the open access movement produces upon the main scholarly communication actors, namely, universities and their researchers, scientific publishers and funding agencies.
\end{abstract}

\section{Keywords}

Open access. Open philosophy. Scholarly communication. Scientific knowledge. Business models of scholarly and scientific publishers. Funding agencies. 


\section{INTRODUÇÃO}

Resultados de um levantamento amplo sobre os efeitos financeiros e não-financeiros de modelos de negócios alternativos para periódicos científicos foram divulgados em relatório recente da Association of Learnerd and Professional Society Publishers (ALPSP, 2005). A primeira frase do relatório é altamente significativa do panorama que se vivencia sobre a questão do acesso aberto à informação científica, nos dias atuais:

As discussões sobre acesso aberto (open access) tendem a ser fortes em retórica, mas pequenas em fatos.

Tomem-se os dois aspectos das discussões sobre acesso aberto presentes na sentença, nomeadamente, retórica e fatos. Observe-se que se relacionam com o quanto se fala e o quanto efetivamente se realiza.

O primeiro - a retórica - refere-se à discussão a respeito do acesso aberto ao conhecimento científico resultante de pesquisas financiadas com recursos públicos como uma das mais acaloradamente discutidas na literatura científica recente, em diferentes áreas do conhecimento. Mais que diferentes áreas do conhecimento, envolve todos os atores da comunidade científica definida em sentido amplo, isto é, constituída dos pesquisadores, editores, bibliotecas, provedores de acesso, agências de fomento, sociedades científicas e outros organismos do contexto acadêmico. Por conseguinte, trata-se de fato de uma discussão forte!

O segundo - os fatos - diz respeito às ações para efetivação do acesso amplo, incondicional e irrestrito ao conhecimento científico gerado como resultado de pesquisa financiada com recursos públicos. São inúmeras ações, em diversos países. Incluem, além dos atores da comunidade científica, governo e parlamento. No entanto, não têm avançado em ritmo que reflita o que se pode considerar uma espécie de "processo de institucionalização" de um novo modelo de negócios para a publicação científica, mais especificamente, para o periódico científico. Conseqüentemente são, de fato, pequenas!

Apesar disso, acesso aberto é tema indiscutivelmente relevante, envolvente e abrangente. Relevante, porque põe em cheque paradigmas da ciência e, como tal, pode contribuir para o surgimento de novos paradigmas. De fato, o que ocorre hoje em relação aos impactos que a questão do acesso aberto provoca nos estudos da comunicação científica pode perfeitamente ser analisado, no contexto de disciplinas que estudam o tema, sob o enfoque do que Thomas Kuhn, em livro amplamente conhecido, considera crise nos desenvolvimentos de uma ciência. Isso, em função das mudanças que introduz no fenômeno, o que, por sua vez, provoca mudanças no modo como é estudado. Envolvente, por motivar o debate acalorado em diferentes contextos, loci e disciplinas. Sem dúvida, trata-se de questão que vem sendo muito discutida na literatura, com diversificados pontos de vista de atores que se mantêm profundamente envolvidos com o tema, como é o caso de Stevan Harnad, verdadeiro evangelista do assunto e um dos precursores da idéia. Abrangente por incluir, de forma crescente, um número cada vez maior tanto de atores quanto de tópicos cobertos na discussão. Motivou, assim, a idéia de uma filosofia que permeia as questões relacionadas ao tema e tanto introduz quanto revela mudanças no cenário da comunicação científica.

\section{FILOSOFIA ABERTA E MUDANÇAS NA COMUNICAÇÃO CIENTÍFICA: PRINCIPAIS INICIATIVAS}

Por "filosofia aberta" (Costa; Moreira, 2003) quer-se definir o movimento observado nos últimos anos em direção ao uso de ferramentas, estratégias e metodologias que denotam um novo modelo de representar um igualmente novo processo de comunicação científica, ao mesmo tempo em que serve de base para interpretá-lo. Compreende, entre outras questões:

- software aberto (ou livre), para o desenvolvimento de aplicações em computador;

- arquivos abertos, para interoperabilidade em nível global; e

- acesso aberto - questão mais polêmica - para a disseminação ampla e irrestrita de resultados da pesquisa científica.

Nesse contexto, a preocupação subjacente parece ser, com efeito, com o acesso tanto amplo quanto rápido ao conhecimento científico. Isso, por sua vez, desencadeou o assim chamado "movimento em favor do acesso aberto à informação científica", implementado por iniciativas que vêm ocorrendo nos últimos cinco anos. Embora haja iniciativas anteriores às mencionadas aqui, como, por exemplo, o ArXiv, de Los Alamos, nos Estados Unidos, e o E-Prints, de Southampton, no Reino Unido, as que se seguem oferecem maiores subsídios à discussão sobre o tema, e permeiam o uso tanto de software aberto quanto de arquivos abertos: 
Filosofia aberta, modelos de negócios e agências de fomento: elementos essenciais a uma discussão sobre o acesso aberto à informação científica

\section{BOAI (Budapest Open Access Initiative, 2002)*}

Movimento que definiu duas estratégias básicas, ambas baseadas no uso do protocolo Open Archives Initiative Protocol for Metadata Harvesting (OAI-PMH). Representa uma das primeiras fortes reações da comunidade científica que ocorreu de forma planejada, organizada e envolvendo uma variedade de atores.

A primeira estratégia, o auto-arquivamento, é definida por Harnad et al. (2001) como a Via Verde (Green Road). Compreende o arquivamento, por parte dos autores, de artigos científicos já publicados ou aceitos para publicação em um periódico referendado. Para isso, obtêm permissão (sinal verde) dos editores que aceitaram seus artigos para publicação, para os depositarem em um servidor de arquivos abertos (repositório) com acesso igualmente aberto*. $\mathrm{O}$ acesso aberto é garantido, assim, quando repositórios de acesso aberto tornam disponíveis, ampla e livremente, artigos já publicados em periódicos científicos referendados e cujo acesso se dá por assinatura, sendo, destarte, restrito.

A segunda estratégia definida em Budapeste, os periódicos eletrônicos de acesso aberto, constituem a Via Dourada (Golden Road) nos dizeres de Harnad et al. (2001). Compreendem os periódicos científicos. eletrônicos cujo acesso aberto a seus conteúdos é garantido pelos próprios editores. Nesse caso, a publicação em ambiente de acesso aberto dá-se, primariamente, no próprio periódico. A contribuição da $\mathrm{BOAI}$ à discussão a respeito do acesso aberto à publicação científica se deve, portanto, a essas duas estratégias que têm norteado as discussões sobre o tema desde então.

É importante lembrar que o objetivo da reunião, de "acelerar o progresso do esforço internacional de tornar artigos de pesquisa em todos os campos acadêmicos livremente disponíveis na Internet", visava, tão somente, ao "acesso aberto à literatura periódica referendada". Nesse contexto, os participantes da reunião definiram acesso aberto como disponibilidade livre e irrestrita. Isso, por sua vez, dá aos leitores "o poder extraordinário de

\footnotetext{
* http://www.soros.org/openaccess/

** Note-se, mais uma vez, a diferença de conceito da palavra "aberto" em arquivos abertos (open archives) e em acesso aberto (open access). No primeiro caso, trata-se de interoperabilidade das máquinas onde estão disponíveis os repositórios de dados, isto é, interface de máquina aberta que facilita tornar disponíveis conteúdos de diversos autores (Lagoze; Van de Sompel, 2001). No segundo, trata-se da acessibilidade ampla e irrestrita a conteúdos disponíveis em formato digital, no sentido em que, como observa Suber (apud Bailey Jr, 2006) "remove barreiras de preço e de permissão ... tornando a literatura científica disponível com o mínimo de restrições de uso".
}

encontrar e usar literatura relevante", e aos autores e seus trabalhos, "visibilidade, legibilidade e impacto vastos e mensuráveis".

Dados empíricos de alguns estudos comprovam essa questão, apontando o acesso aberto a resultados de pesquisa como fator que maximiza o acesso à pesquisa propriamente dita. Como observam Brody; Harnad (2004), "o acesso aberto maximiza e acelera o impacto das pesquisas e, conseqüentemente, sua produtividade, progresso e recompensas".

Lawrence (2001) apresenta resultados de um estudo que mostrou crescimento de $336 \%$, em média, nas citações a artigos disponíveis on-line, em relação a artigos publicados off-line, na mesma fonte. Os resultados do estudo de Lawrence, amplamente citados na literatura (mais de 700 citações no Google, de acordo com Antelman, 2004), estão em acordo com o estudo realizado por Harnad; Brody na área de física (Lawrence estudou a área de computação), em que a taxa de citações a artigos com acesso livre em relação a citações a artigos com acesso restrito variou de 2.5:1 a 5.8:1 (Jones et al., 2006, p. 27).

Antelman (2004) estudou quatro disciplinas, nomeadamente, filosofia, ciência política, engenharia elétrica e eletrônica e matemática. Seus resultados também mostraram que artigos com acesso aberto têm maior impacto do que os artigos que não estão disponíveis livremente, mesmo entre disciplinas de diferentes divisões do conhecimento e a despeito de diferenças entre as disciplinas (Antelman, 2004, p. 379).

A conclusão, portanto, aponta para um processo cíclico em que maior acessibilidade é igual a maior uso, que significa maior fator de impacto, que, por sua vez, significa maiores recompensas, que provocam mais produção, a qual, estando mais acessível, provoca maior uso e assim sucessivamente. No entanto, como se trata de assunto ainda incipiente, é necessário maior número de estudos para que se possa ter uma imagem mais acurada da questão.

\section{Reunião de Bethesda (2003)*}

Foi durante essa reunião que se definiu o que são publicações de acesso aberto. Dessa definição - seminal têm sido direcionados debates e decisões cruciais que vêm mudando o panorama da comunicação científica no mundo. Trata-se de uma "declaração de princípios", cujo propósito foi estimular a discussão sobre como

* http://www.earlham.edu/ peters/fos/bethesda.htm 
atingir, o mais rapidamente possível, a meta de prover acesso aberto à literatura científica primária. Para isso, os participantes definiram "publicação de acesso aberto" como as que preenchem duas condições:

A primeira é que autores e detentores de direitos autorais devem assegurar a todo usuário:

- direito livre, irrevogável e perpétuo de acesso a seus trabalhos;

- licença para copiar, usar, distribuir, transmitir e exibir trabalhos publicamente, elaborar e distribuir trabalhos derivados, em qualquer meio digital, para qualquer propósito responsável, sujeito à atribuição apropriada de autoria, assim como fazer um número pequeno de cópias impressas para uso pessoal.

A segunda é que uma versão completa do trabalho publicado, assim como de todo material suplementar, incluindo uma cópia da permissão citada na primeira condição, em formato eletrônico apropriado, devem ser depositados, imediatamente após a publicação inicial, em pelo menos um repositório on-line. Este, por sua vez, deve ser mantido por uma instituição acadêmica, sociedade científica, agência governamental ou outra instituição bem estabelecida que busque permitir o acesso livre, a distribuição irrestrita, a interoperabilidade e o arquivamento em longo prazo.

Como se pode observar, as questões definidas na reunião de Bethesda ratificam o que já havia sido proposto em Budapeste que, por sua vez, ratificou práticas como as de Los Alamos e Southampton. É importante ressaltar que o documento gerado nessa reunião representa a posição dos principais atores envolvidos no processo de comunicação científica, destacando-se, neste, a questão da publicação. Isso porque a noção que permeou a declaração de princípios elaborada visou a envolver os seguintes atores do processo nos passos que precisam ser dados para promover a transição rápida e eficiente à publicação de acesso aberto:

- as agências de fomento, que apóiam e sustêm a pesquisa científica;

- os cientistas, que geram os resultados das pesquisas;

- os editores, que facilitam a revisão pelos pares e a distribuição dos resultados da pesquisa;
- todos aqueles que dependem do acesso a esse conhecimento, incluindo os próprios pesquisadores e os bibliotecários, entre outros.

Além de definirem o que seja publicação de acesso aberto, os participantes da Reunião de Bethesda elaboraram três declarações, por três grupos de trabalho, nomeadamente, instituições de pesquisa e agências de fomento; bibliotecários e editores; pesquisadores e sociedades científicas. As declarações de cada grupo são significativas do espírito (ou da filosofia) que está subjacente à questão do acesso aberto. Vale a pena ressaltar alguns dos pontos identificados nas declarações de cada grupo, cujos componentes, na verdade, eram representantes individuais, no sentido em que não falavam por suas instituições, mas por si próprios:

- Grupo de trabalho dos indivíduos vinculados a instituições de pesquisa e agências de fomento: considerou, entre outras questões, que a missão de compartilhar idéias e descobertas por meio da publicação é "completada pela metade, se o trabalho não se torna tão amplamente disponível e útil à sociedade quanto possível". Nesse sentido, declaram, no primeiro dos quatro pontos ressaltados na declaração do grupo, que encorajam seus pesquisadores e beneficiados com bolsas de pesquisa a "publicarem seus trabalhos de acordo com os princípios do modelo de acesso aberto, para maximizar o acesso e beneficiar cientistas, estudiosos e o público em todo o mundo".

É o que têm feito instituições como a National Institutes of Health, nos Estados Unidos e a Wellcome Trust, no Reino Unido. Uma descrição sucinta do trabalho dessas agências de fomento à pesquisa é apresentada na seção 4 . $\mathrm{Na}$ Índia, o National Institute of Technology determinou que toda publicação de pesquisa de autoria de professores e estudantes seja depositada em um repositório de acesso aberto.

- Grupo de bibliotecários e editores: considerou que "o acesso aberto será um componente essencial da publicação científica no futuro" e que "resultados de pesquisa científica devem ser tão abertamente acessíveis e livremente usáveis quanto possível". Estão, como se pode notar, em perfeito acordo com seus co-partícipes na reunião e antes dela. Separadamente, os participantes do grupo estabeleceram declarações de apoio e compromisso com a política do acesso aberto.

Antelman (2005, p. 379) observa que os resultados de seu estudo podem ajudar bibliotecários nessas tarefas. 
Para isso, considera que devem trabalhar em iniciativas tais como criar repositórios institucionais, buscar alternativas para publicações com acesso aberto e auxiliar docentes pesquisadores nas universidades a negociar direitos autorais com editores. Foi certamente com essas idéias em mente que Barton; Walker (2003; 2004-2005) criaram o DSpace, hoje um dos modelos mais utilizados na criação de repositórios institucionais em universidades.

- Grupo de pesquisadores e sociedades científicas: considerou, de modo similar aos outros dois grupos, que tanto os cientistas quanto as sociedades científicas que os representam têm "grande interesse em assegurar que resultados de pesquisa sejam disseminados tão imediata, ampla e efetivamente quanto possível". Estabeleceram declarações em favor do acesso aberto, comprometendose a "educar seus colegas, membros e o público sobre a importância do acesso aberto e por que o apóiam”.

Dentre os pesquisadores, Suber (2006)* parece ter tomado esse compromisso como evangelho que deve ser anunciado "a toda criatura". O autor tem, desde a reunião em Budapeste, publicado grande número de trabalhos sobre o assunto, além de advogá-lo com convicção. No que concerne às sociedades científicas, informação baseada no "grande interesse" em disseminar ampla e efetivamente resultados de pesquisa é encontrada na página da Max Planck Society, da Alemanha**. Outras sociedades científicas têm caminhado nessa direção.

Impressiona a aparente unanimidade de posicionamento dos participantes da Reunião de Bethesda em relação ao acesso "amplo". Apesar disso, no entanto, ainda não se observa a mesma adesão em nível mundial. Uma explicação pode estar baseada no fato de que pesquisadores de países não representados naquela e em outras reuniões, e fora das discussões que se seguiram a elas, ainda temem, desconsideram, desconfiam de publicações disponíveis em ambiente de acesso aberto. Chegam a considerar que não têm validade científica! Como informou Arunachalam, em uma lista de discussão (JISC, 2006): "mesmo hoje, muitos cientistas que publicam na Índia, em todos os níveis, de estudantes de doutorado a professores seniors, decanos, pró-reitores e diretores de laboratórios de pesquisa são 'felizes' (blissfully) ignorantes a respeito do acesso aberto".

\footnotetext{
* Para acesso de grande número de textos importantes sobre acesso aberto, acessar a página do autor em: http://www.earlham.edu/ peters/ hometoc.htm

** http://www.mpg.de/english
}

Não parecem pertinentes preocupações e desconfianças, à medida que a revisão pelos pares tem sido ressaltada em todas as ocasiões em que se discute a questão. Permanece, portanto, como questão invariável, apesar das mudanças significativas no processo de comunicação científica em outras questões relacionadas ao acesso aberto. Isso, em contrapartida, garante os critérios de qualidade requeridos pela comunidade científica para as publicações de resultados de pesquisa e dissipa preocupações desse tipo.

\section{Declaração de Berlim (2003)*}

Documento que tem sido replicado em todo o mundo, compreende os resultados de reunião realizada primeiramente em 2003, depois, anualmente (2004, 2005, 2006). Certamente, se repetir-se-á pelos próximos anos, enquanto for relevante discutir o movimento em favor do acesso aberto à informação e todas as questões que lhe são subjacentes. A reunião de 2003, intitulada "Open Access to Knowledge in the Sciences and Humanities", visou a promover a Internet como o "instrumento funcional para uma base global de conhecimento científico e reflexão humana", e a especificar medidas que "formuladores de política, instituições de pesquisa, agências de fomento, bibliotecas e museus precisam considerar".

Observe-se a presença de museus entre os atores: isso se deve ao fato de que a reunião enfocou tanto o conhecimento resultante da pesquisa científica quanto o que representa a herança cultural das nações. Há um número grande de projetos sendo realizados, especialmente na Europa, visando à preservação e disseminação da herança cultural das nações. $\mathrm{O}$ acervo desses conhecimentos tornados disponíveis em repositórios de acesso aberto representam, sem dúvida, uma contribuição significativa e sem precedentes à história da civilização humana.

Note-se que, com essa filosofia, a declaração ratifica as decisões de Budapeste e Bethesda, além de adicionar as da European Cultural Heritage Online (ECHO)**. A edição de 2005 da Reunião, em Southampton, Inglaterra, adicionou as seguintes recomendações - polêmicas e que requerem mudança no ethos da ciência - às decisões anteriores:

"A fim de implementar a Declaração de Berlim, as instituições devem:

\footnotetext{
* http://www.zim.mpg.de/openaccess-berlin/index.html

** http://echo2.mpiwg-berlin.mpg.de/home
} 
- implementar uma política para requerer de seus pesquisadores que depositem em um repositório de acesso aberto uma cópia de todos os seus artigos publicados; e

- encorajar seus pesquisadores a publicar seus artigos de pesquisa em periódicos de acesso aberto - onde haja um periódico apropriado - e prover o apoio necessário para que isso aconteça.”

Alguns exemplos de implementações estão dados nos parágrafos anteriores. Recentemente, o Brasil deu mais um passo importante nessa direção, quando, na 58 Reunião Anual da SBPC, foi elaborada uma "Carta aberta à SBPC"*. O documento orienta sociedades científicas a que se posicionem nesse sentido e requer (por meio da ação da SBPC) das instituições brasileiras que envidem esforços no sentido de implementar as iniciativas no país. A carta tanto se baseia em, quanto ratifica quatro documentos anteriores: o Manifesto Brasileiro em Favor do Acesso Aberto (2005)**, as declarações de Salvador (2005)***, a Declaração de Florianópolis (2005)**** e a Carta de São Paulo (2005)*****. Ibict, Bireme e Anpepp têm exercido, de fato, um papel essencial para que o Brasil discuta e implemente ações nesse sentido. É importante que a comunidade científica brasileira, por meio de todos os seus atores (pesquisadores e suas universidades, editores, sociedades científicas, agências de fomento e bibliotecários, entre outros), responda aos desafios e ações já implementadas por essas três instituições. As sociedades científicas, de modo especial, têm papel determinante nesse processo.

\section{Em conclusão: a inexorabilidade do acesso aberto à informação científica}

Os impactos das iniciativas descritas nessa seção auxiliam na identificação do acesso aberto à informação científica como um dos componentes essenciais da filosofia aberta que permeia as discussões sobre mudanças no processo de comunicação científica como resultado da introdução de tecnologias de informação e comunicação no ambiente da pesquisa. A filosofia aberta, por sua vez, reflete o movimento inexorável em direção ao uso de ferramentas e recursos que visam a integrar o maior número possível de beneficiados do acesso à informação.

\footnotetext{
* http://blogdokura.blogspot.com

** http://www.ibict.br/openaccess/arquivos/manifesto.htm

*** http://www.icm19.org

**** http://www.bvs-psi.org.br/DeclFlor.pdf

***** http://www.acessoaberto.org/carta_de_sao_paulo_acesso_ aberto.htm
}

Em razão disso, parecem necessários, no ambiente da publicação científica, modelos de negócios alternativos para o periódico científico como solução para o acesso amplo ao conhecimento. Vislumbra-se também, nesse cenário, a necessidade vital de que agências de fomento tanto se posicionem a respeito da questão quanto implementem decisões e ações nessa direção. As seções seguintes centram a atenção nessas duas questões (modelos de negócios e agências de fomento), com o objetivo de acalorar a discussão.

\section{O ACESSO ABERTO, OS MODELOS DE NEGÓCIOS ALTERNATIVOS E AS DIFERENÇAS DISCIPLINARES}

Uma análise feita por Bailey Jr. (2006) sobre definições de acesso aberto revelou pelo menos sete pontos-chave. O primeiro é que trabalhos com acesso aberto estão livremente disponíveis. O segundo é que esses trabalhos estão disponíveis on-line, isto é, são documentos digitais disponíveis na Internet. $O$ terceiro é que são trabalhos científicos. $\mathrm{O}$ quarto é que os autores desses trabalhos não são pagos pelos seus esforços. $O$ quinto é que, como a maioria dos autores de artigos publicados em periódicos referendados não é paga, e esses trabalhos são científicos, os artigos são identificados como o tipo primordial de material de acesso aberto. Sexto, há um extraordinário número de usos permitidos para material de acesso aberto. Sétimo, há duas estratégias-chave para o acesso aberto: o auto-arquivamento e os periódicos de acesso aberto. Esses pontos-chave, como é de se notar, são uma espécie de resumo do que outros autores consideram acesso aberto. Bailey Jr. acrescenta a idéia de Suber (2006) de que "o conceito central de acesso aberto se caracteriza por remover barreiras de preço (assinatura) e de permissão (restrições de licença e copyright)" para fazer surgir a "literatura livre de royalties". Observe-se, claramente, o aparecimento de novos modelos de negócios para essa literatura, resultado da necessidade da remoção de barreiras e inserção de liberdade, ambas de acesso. É o que se discute brevemente na seção seguinte.

\section{Modelos de negócios}

Costa (2005) chama a atenção para as questões relacionadas ao modelo de publicação da pesquisa que domina o cenário mundial. Nele, editores comerciais atribuem preços excessivos e impõem barreiras de permissão sobre publicações de pesquisas que são amplamente financiadas com recursos públicos. De fato, como observa Johnson (2002), o sistema de comunicação científica atual "limita, mais do que expande, a 
Filosofia aberta, modelos de negócios e agências de fomento: elementos essenciais a uma discussão sobre $o$ acesso aberto à informação científica

disponibilidade e legibilidade (readership) da maior parte da pesquisa científica (ao tempo que obscurece suas origens institucionais)". Isso em razão dos custos crescentemente altos de assinatura dos periódicos e a escassez, igualmente crescente, de recursos por parte das bibliotecas e dos próprios pesquisadores para assiná-los. Têm sido vários os autores que não somente discorrem sobre o assunto, mas apresentam resultados empíricos de estudos que apontam para a necessidade de modelos de negócios alternativos, ao tempo que realizam e relatam experimentos sobre novos modelos.

Em um trecho do documento da BOAI, diz-se que "experimentos têm mostrado que os custos totais de provisão de acesso aberto à literatura são muito mais baixos que os custos das formas tradicionais de disseminação". Em outro, ressalta-se que "atingir acesso aberto requer novos modelos de recuperação de custos (o processo de publicação é dispendioso!) e mecanismos de financiamento, mas os custos significativamente mais baixos de disseminação são a razão para se confiar que a meta é atingível e não preferível ou utópica”.

Na tentativa de prover dados empíricos sobre essas questões, um estudo recente realizado pela Association of Learned and Professional (ALPSP) identificou que o movimento em favor do acesso aberto criou um ambiente em que vários modelos de negócios "estão sendo desafiados, enquanto outros estão sendo testados". O documento com o relatório do estudo acrescenta que, embora o modelo baseado em assinaturas ainda domine esse cenário, no sentido em que detém o maior número de periódicos, os editores dessas revistas têm interesse em testar outros modelos. Em um deles, os autores pagam para publicar e as publicações depois ficam disponíveis livremente. Nesses, espera-se que as preocupações financeiras recaiam sobre as agências de fomento, interessadas que são na distribuição ampla das pesquisas que financiam (ALPSP, 2005).

As observações do estudo da ALPSP são de que "não há dúvidas de que editores tradicionais de todos os tipos e tamanhos, que requerem assinatura, estão sentindo o impacto do movimento em favor do acesso aberto e precisando responder de algum modo". Talvez por isso, são vários, hoje, os modelos de negócios possíveis para a publicação de periódicos. Entre eles, a ALPSP identificou e enumera:

- assinatura, tanto para fascículos novos como para os anteriores;
- acesso aberto postergado (delayed open access): assinatura para acesso com o editor, mas permissão para depósito em repositório de acesso aberto, após um período determinado de tempo;

- assinatura e experimento opcional com acesso aberto;

- assinatura para a maioria, mas alguns conteúdos novos disponíveis livremente; financiamentos por grants; conteúdos anteriores com acesso livre;

- acesso aberto total (full open access), apoiado por assinaturas das versões impressas e por taxas pagas pelos autores;

- acesso aberto total, apoiado por taxas pagas pelos autores, membros e assinaturas de outros títulos impressos;

- acesso aberto total, apoiado por taxas pagas pelos autores, membros institucionais, grants e indústria;

- acesso aberto total, apoiado por membros;

- acesso aberto total, apoiado por propaganda;

- acesso aberto total, anteriormente, migrando para acesso aberto postergado;

- assinatura para instituições, livre para indivíduos;

- assinatura para a maioria dos conteúdos novos, alguns novos conteúdos livres e conteúdos anteriores livres;

- acesso aberto para pre-prints, assinatura para novos conteúdos e livre para conteúdos anteriores;

- assinatura, primeiro, e acesso aberto postergado.

Permanece, no entanto, a questão de que os modelos em que o autor paga pela publicação não parecem levar em conta diferenças entre países "centrais" e países "periféricos". Na hipótese de esse modelo se estabelecer, o que preocupa, portanto, é que em países ricos, as instituições dos autores e as agências de fomento têm dinheiro para financiar tanto a pesquisa quanto a publicação dos resultados. Os pesquisadores dos países ditos "periféricos" continuariam com problemas, pois, além de terem menos recursos para a pesquisa propriamente dita, não os terão para a publicação dos resultados. Quanto às editoras, mais cedo ou mais tarde vão ter de criar novos modelos de negócios. Algumas, como mostrou a ALPSP, já o fizeram. É muito provável 
que esses vários modelos coexistam. Só não é possível visualizar se, por exemplo, existirão diferentes modelos de negócios para os periódicos eletrônicos em função dos diferentes padrões de comunicação de comunidades científicas de diferentes divisões do conhecimento.

Diferenças disciplinares constituem uma questão importante à medida que se têm constituído uma das invariâncias do processo de comunicação científica, tal como a avaliação pelos pares. Isto é, assim como a avaliação pelos pares permanece como requisito de qualidade da publicação científica, sejam quais forem as facilidades que as tecnologias de informação e comunicação ofereçam, as diferenças nos padrões de comunicação de pesquisadores de diferentes divisões do conhecimento tendem, igualmente, a permanecer inalteráveis. Um número grande de estudos aponta para essas questões. Exemplos são relatados na seção a seguir.

\section{Diferenças disciplinares}

Antelman (2004) divulgou resultados do estudo que realizou em quatro disciplinas: filosofia, ciência política, engenharia elétrica e eletrônica e matemática. $\bigcirc$ estudo de Antelman se norteou pelas diferenças disciplinares tópico essencial nesta e em quaisquer discussões concernentes à comunicação científica -, em relação ao estágio de cada disciplina na adoção do acesso aberto. Observe-se, nesse aspecto, que Antelman incluiu disciplinas das três divisões do conhecimento: artes e humanidades; ciências sociais e humanas; e ciências exatas e naturais. Seu objetivo foi identificar se artigos dessas áreas do conhecimento tinham maior impacto, medido pelas citações no Web of Science, quando seus autores os deixavam disponíveis am ambiente de aceso livre na Internet. Os resultados de Alteman mostraram que artigos disponíveis livremente têm, de fato, maior impacto, a despeito das diferenças entre os resultados de cada disciplina.

Uma questão que é importante considerar nesse contexto é a do impacto da pesquisa disponível em repositórios de acesso aberto. Antelman (op. cit., p. 377) identificou que artigos disponíveis em repositórios de acesso aberto têm, de fato, maior fator de impacto. Nesse sentido, revelou que "pesquisadores de disciplinas diversas estão adotando práticas do acesso aberto e sendo recompensados por isso". Isso porque seus dados mostraram uma diferença significativa nas taxas médias de citação de artigos com acesso aberto e dos que não estão disponíveis livremente, nas quatro disciplinas. No entanto, os níveis de adoção do acesso aberto entre as disciplinas foram mais baixo em filosofia e mais alto em matemática. Segundo o autor, "embora as pesquisas venham mostrando que cientistas preferem acessar seu material de pesquisa online, e esse pode também ser o caso dos cientistas sociais, isso pode não ser verdade para os humanistas".

Diferenças disciplinares constituíram o foco central da pesquisa de Allen (2005), que estudou a atitude de cientistas sociais e humanistas do Reino Unido em relação a depositar seus trabalhos em repositórios institucionais de acesso aberto. $\mathrm{O}$ autor deixa clara a diferença de atitude e comportamento de cientistas sociais e humanistas em relação a cientistas das áreas naturais e exatas.

Essa é, indubitavelmente, uma questão recorrente na ciência da informação: humanistas são tardios em adotar inovações tecnológicas, em relação a seus colegas pesquisadores das ciências exatas e naturais. Cientistas sociais, como já sedimentado na literatura, dadas todas as outras questões relacionadas a esse tema, assumem uma posição intermediária entre os outros dois grupos.

Os repositórios digitais de acesso livre representam, evidentemente, uma inovação. Como tal, tendem a ser adotados mais precocemente por cientistas das áreas exatas e naturais, e mais tardiamente pelos pesquisadores do outro extremo do continuum, os humanistas. Destarte, a maior conclusão de Allen, em relação a uma variedade de estudos sobre uma igualmente variedade de tópicos, foi de que

há, definitivamente, diferenças de atitude e comportamento de pesquisadores acadêmicos de diferentes áreas do conhecimento em relação a depositar seus trabalhos em repositórios institucionais. $\bigcirc$ comportamento atual de pesquisadores das áreas de artes, humanidades e ciências sociais indica níveis muito mais baixos de depósitos por parte desses pesquisadores, se comparados com aqueles das áreas de ciências exatas e naturais.

A qualidade da informação científica é validada pelo processo de revisão pelos pares. As diferenças nos padrões de comunicação da pesquisa são determinadas pelo ethos nas comunidades científicas de cada divisão do conhecimento. É possível, portanto, inferir que tanto revisão pelos pares quanto diferenças nos padrões de comunicação acabam por ser determinantes dos recursos, estratégias, metodologias e políticas relacionadas a qualquer aspecto do processo de comunicação da ciência. Compreendem, por conseguinte, questões indispensáveis 
Filosofia aberta, modelos de negócios e agências de fomento: elementos essenciais a uma discussão sobre $o$ acesso aberto à informação científica

a serem levadas em conta por universidades, editoras, agências de fomento, sociedades científicas ou quaisquer outros organismos constituintes do ambiente em que pesquisadores realizam a comunicação da ciência. É importante notar, no entanto, que parecem ser as agências de fomento que exercem papel crucial nesse contexto, como discutido a seguir.

\section{O ACESSO ABERTO E AS AGÊNCIAS DE FOMENTO}

Toda a discussão sobre acesso aberto gira em torno de duas questões. A primeira diz respeito à reação dos pesquisadores ao modelo de negócios das editoras comerciais. Isto é, aos fins lucrativos das principais editoras científicas. Fala-se aqui de editoras de periódicos científicos, sem deixar de ter clara a idéia de que periódicos não são o veículo de comunicação preponderante de todas as áreas do conhecimento. No entanto, é no contexto da publicação periódica que as principais mudanças vêm ocorrendo e em que e o modelo de negócios constitui o foco central.

O modelo, como é amplamente conhecido, consiste, dentre outras, de cinco ações básicas:

- autores são financiados por suas instituições ou por agências de fomento (maioria esmagadora dos casos, em todo o mundo) para realizarem suas pesquisas;

- autores realizam pesquisas, escrevem sobre seus resultados e submetem seus manuscritos a um editor;

- editores solicitam parecer sobre os manuscritos a pesquisadores especialistas na área de interesse;

- se aceito o trabalho, editores o publicam;

- a audiência desses pesquisadores autores tem o acesso a seus trabalhos restringido pelos custos das assinaturas dos periódicos em que publicaram.

Observe-se a perversidade do modelo: universidades e agências de fomento financiam o trabalho dos pesquisadores e depois esses mesmos pesquisadores e suas bibliotecas não podem ter acesso a seus resultados publicados. Era, portanto, de se esperar uma reação dos pesquisadores ao modelo, diante das facilidades oferecidas pelas tecnologias de informação e comunicação.

Na verdade, a questão do preço das assinaturas tem sido uma das principais, se não a principal motivação para o movimento do acesso aberto. Prosser (2003) chama atenção para o fato de que por três séculos o modelo básico para a comunicação científica nas ciências exatas e naturais permaneceu imutável, com o periódico científico no papel central. Contudo, observa Prosser,

a confluência dos preços crescentes dos editores, os orçamentos restritos das bibliotecas e as novas tecnologias eletrônicas de comunicação estão criando o ambiente certo para uma transformação marcante em como se compartilham novas informações dentro da comunidade desses cientistas.

A segunda questão dessa discussão, resultante da primeira, refere-se à idéia de que pesquisas financiadas com recursos públicos devem estar publicamente acessíveis. Sobre essa questão, o modelo adotado atualmente por editores comerciais implica a atribuição de preços excessivos e a imposição de barreiras de permissão sobre publicações de pesquisas que são amplamente financiadas com recursos públicos. Tornase, portanto, necessário considerar o que observa Alberts (2002), ao afirmar que a informação científica e técnica é, fundamentalmente, um bem público global, que deve estar livremente disponível para o benefício de todos.

É nesse ponto que entram as agências de fomento, sem dúvida, balizas para o trabalho dos pesquisadores. Isso porque lhes monitoram a produção intelectual, avaliamna (e aos próprios pesquisadores, seus programas de pósgraduação e suas instituições), classificam-nos (e às publicações que geram como resultado de seu trabalho de pesquisa) e os fomentam ou não, a depender das três ações anteriores! Essa análise aponta para uma espécie de 'taxonomia da ação das agências sobre os pesquisadores', dado que, além de ser uma categorização dessas ações, denota um caráter cumulativo delas. E, mundialmente, implacável.

Nesse contexto, agências de fomento assumem papel primordial como atoras nas comunidades científicas. Sim, porque, se balizadoras da atividade dos pesquisadores, certamente apontam o caminho "aceitável" (quer se queira ou não) a tomar. Mesmo não lhes cabendo tal atribuição, estão na mente dos pesquisadores como se assim fora.

Observe-se que essa questão põe em xeque o ethos da ciência. Reforça o papel de governos e parlamento em relação às comunidades científicas e ao processo de comunicação da ciência. Instiga o debate. Desafia as agências de fomento a se colocarem no seu front. 
Chan; Costa (2005) ressaltam as experiências dos governos americano e britânico com relação ao papel que governo e agências de fomento exercem nesse contexto e que reflexo isso tem sobre editores comerciais e seus modelos de negócios, em função do acesso aberto. Os autores comentam que nos países ricos esses organismos

estão começando a questionar a eficiência do sistema de publicação atual, dominado por interesses comerciais, e estão começando a demandar que a pesquisa que eles financiam esteja tão amplamente acessível quanto possível.

No caso britânico, o Wellcome Trust, maior instituição privada de financiamento do Reino Unido, anunciou seu apoio às iniciativas com acesso livre em 2003. O Comitê de Ciência e Tecnologia da House of Commons tem publicado, desde julho de 2004, relatórios com resultados de levantamentos sobre essa questão (acesso a publicações científicas) no país. Duas das inúmeras recomendações do primeiro relatório são destacadas no artigo de Chan; Costa:

governo deve prover fundos para todas as universidades do Reino Unido criarem repositórios institucionais de acesso livre.

Os autores de artigos baseados em pesquisa financiada pelo governo devem depositar cópias deles em seus repositórios institucionais.

No caso americano, Chan; Costa (op. cit.) destacam a decisão da House of Representatives de que o National Institutes of Health (segunda maior instituição de financiamento para pesquisa nos Estados Unidos) desenvolva uma política de requerer que cientistas financiados pela instituição depositem seus artigos no PubMedCentral (repositório do NIH), quando aceitos para publicação em um periódico.

Há outras iniciativas em outros países. Há reações fortes dos editores. Há um debate acalorado. Há mudanças em curso. Entretanto, não se observa um claro movimento no Brasil, nesse sentido, por parte da comunidade científica definida em sentido amplo. Urge, portanto, que as agências de fomento do país considerem a importância do tema. Tomem a via verde. Apóiem, viabilizem, reconheçam o acesso aberto.

\section{REFLEXÕES FINAIS: IMPACTOS DO ACESSO ABERTO SOBRE ATORES DA COMUNIDADE CIENTÍFICA}

O movimento em favor do acesso aberto à informação científica pode ser analisado sob diferentes enfoques. Um deles, um dos mais debatidos na literatura, diz respeito aos impactos que provoca. Para efeito das reflexões conclusivas deste trabalho, é importante considerar os impactos do movimento sobre três grupos de atores da comunidade científica.

\section{Impacto sobre as universidades (dilema dos seus} pesquisadores-autores)

Universidades, como o locus predominante das atividades de pesquisa, têm como um de seus mais importantes valores seu quadro de docentes (e discentes!) pesquisadores. Nesse sentido, avaliar o impacto do acesso aberto sobre as universidades é fazê-lo sobre os pesquisadores, individualmente e como membros da comunidade universitária. Isso tende a promover um impacto sobre os autores no sentido em que provoca um dilema que envolve dois pontos:

- o interesse dos docentes-pesquisadores como autores é a maximização do impacto de seus resultados. $O$ acesso aberto, por meio do autoarquivamento (mudança no papel como atores do sistema de publicação) e dos periódicos eletrônicos de acesso aberto garantem isso;

- a necessidade de reconhecimento da publicação eletrônica em ambiente aberto, por parte da comunidade científica como um todo e, em particular, das universidades (salários, promoções na carreira e financiamentos) e agências de fomento (recursos para pesquisa).

Impacto sobre editores comerciais (pressão da comunidade científica)

A pressão da comunidade científica hoje, definida em sentido restrito, isto é, formada principalmente por pesquisadores, é de que sejam removidas as barreiras de acesso e permissão à publicação. Os preços excessivos de assinatura de venda de publicações apontam, sem dúvida nenhuma, e de forma inexorável, para a necessidade de novos modelos de negócios para a publicação científica.

Nesse contexto, visibilidade constitui uma questão crucial, tanto para os pesquisadores quanto para suas instituições. Como já diagnosticado na literatura, o acesso 
Filosofia aberta, modelos de negócios e agências de fomento: elementos essenciais a uma discussão sobre o acesso aberto à informação científica

aberto aumenta significativamente a visibilidade das pesquisas. Não é de estranhar, portanto, a pressão que pesquisadores vêm exercendo sobre as editoras dos seus trabalhos para que lhes removam as barreiras de acesso.

\section{Impacto sobre as agências de fomento (desafio de mudar a visão e as políticas)}

Questionamentos sobre o sistema atual de publicação (necessidade de que pesquisas financiadas estejam tão amplamente acessíveis quanto possível) têm provocado ações por parte de grandes agências de fomento nos países desenvolvidos. Na verdade, por parte de algumas das maiores agências e fomento. Isso, contudo, tem-se dado no âmbito das ciências naturais, mais especificamente das ciências da vida, como é o caso do National Institutes of Health (Estados Unidos) e do Wellcome Trust, (Reino Unido). De fato, o entendimento de que os recursos despendidos com pesquisa só se justificam se seus resultados estiverem amplamente acessíveis constitui a visão que se espera, hoje, dessas agências. Mais que isso, constitui uma nova visão sobre a validade da publicação científica, visto que desafia modelos já estabelecidos. Provoca, por conseguinte, temores no seio das comunidades científicas, que se balizam pelas ações das agências. É preciso, no entanto, encarar o desafio e mudar, de fato, o modelo do processo de comunicação científica, tanto no que concerne aos papéis tradicionalmente desempenhados por seus atores quanto no que diz respeito aos formatos da publicação científica.

A discussão dessas questões aponta para a necessidade de estudos que forneçam dados necessários à tomada de decisão dos diferentes atores do processo de comunicação científica em todo o mundo sobre as questões do acesso aberto. Decisões claras por parte das agências de fomento quanto à adoção ou não de uma filosofia aberta para nortear a pesquisa e sua publicação são necessárias, à medida que balizam o ethos da ciência em todos os campos do conhecimento. Este, por sua vez, apontará quais serão os novos modelos de negócios da publicação científica.

Não parece restar dúvidas, portanto, de que a filosofia aberta tende a se constituir no fundamento inexorável da comunicação científica daqui por diante. Sua adoção tende, no entanto, e em função de diferenças disciplinares, a se constituir em uma questão de tempo. Como proposto no modelo de adoção de inovações de Rogers (1995), há os adotantes precoces (pesquisadores das ciências exatas e naturais) e os adotantes tardios (cientistas sociais e humanistas). Esperemos e vejamos.

\section{REFERÊNCIAS}

ALBERTS, B. Engaging in a worldwide transformation: our responsibility as scientists for the provision of global public goods, President's Address to the Fellows of the Washington D.C.: National Academy of Sciences, 29 April 2002.

ALLEN, James. Interdisciplinary differences in attitudes towards deposit in institutional repositories. Disponível em: < http://eprints.rclis.org/archive/ 00005180/01/FULLTEXT.pdf>. Acesso em: 13 jan. 2006.

ASSOCIATION OF LEARNED AND PROFESSIONAL SOCIETIES PUBLISHERS. The facts about open access: a study on financial and non-financial effects of alternative business models for scholarly journals. Disponível em: < http://www.alpsp.org/publications/ FAOAcompleteREV.pdf $>$. Acesso em: 2006.

ANTELMAN, K. Do open access articles have a greater research impact?. College $\mathcal{E}$ Research Libraries, v. 65, n. 5, p. 372-382, May 2004.

BARTON, M; WALKER, J. H. Building a business plan for Dspace, MIT libraries' digital institutional repository. Journal of Digital Information, v. 4, n. 2, May 2003. Disponível em: < http://jodi.tamu.edu/ Articles/v04/i02/Barton/barton-final.pdf $>$. Acesso em: 2006.

. Creating an institutional repository: LEADIRS workbook. Cambridge: MIT-Libraries, c2004-2005. (Learning about digital institutional repositories). Disponível em: $<$ http://www.dspace.org/ implement/leadirs.pdf $>$. Acesso em: 2006.

BAILEY Jr., Charles. What is open access? In: JACOBS, N., (Ed.). Open access: key strategic, technical and economic aspects. Oxford:

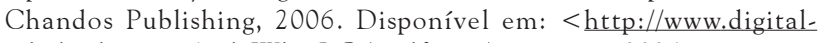
scholarship.com/cwb/WhatIsOA.pdf >. Acesso em: 2006.

BRODY, Tim; HARNAD, Stevan. The research impact cycle. Disponível em: < http://opcit.eprints.org/feb19oa/harnad-cycle.ppt>. Acesso em: 17 set. 2004.

CHAN, Leslie; COSTA, Sely. Participation in the global knowledge commons: challenges and opportunities for research dissemination in developing countries. New Library World, n. 3/4, Apr. 2005.

COSTA, Sely M. S. O novo papel das tecnologias digitais na comunicação científica. In: SAYAO, L. F. et al. (Org.). Bibliotecas digitais: saberes e práticas. Salvador/Brasília: UFBA/IBICT, 2005. p. 167-183.

; MOREIRA, Ana Cristina S. The diversity of trends, experiences and approaches in electronic publishing: evidences of a paradigm shift on communication. In: COSTA, S. M. S et al. FROM INFORMATION TO KNOWLEDGE: ICCC/IFIP INTERNATIONAL CONFERENCE ON ELECTRONIC PUBLISHING, 7., 2003, Portugal. Proceedings... Guimarães: Universidade do Minho, 2003. p. 5-9.

HARNAD, Stevan et al. The access/impact problem and the green and gold roads to open access. 2001. Disponível em: < http://www.ecs.soton.ac.uk/ 〜harnad/Temp/impact.html >. Acesso em: 18 jul. 2004.

JISC discussion list. List maintained by JISC Digital Repositories Programme. Disponível em: <jisc-repositories@jiscmail.ac.uk>. Acesso em: 11 de mar. 2006.

JOHNSON, Richard K. Partnering with faculty to enhance scholarly communication. D-Lib Magazine, v. 8, n. 11, Nov. 2002. Disponível em: <http://www.dlib.org/dlib/november02/johnson/11johnson.html>. Acesso em: 23 maio 2005.

JONES, Richard et al. The institutional repository. Oxford: Chandos Publishing, 2006.

LAWRENCE, Steve. Free online availability substantially increases a paper's impact: nature webdebates. Disponível em: < http://www.nature.com/ 
Sely M. S. Costa

nature/debates/e-access/Articles/lawrence.html>. Acesso em: 20 nov. 2004.

PROSSER, David. Information revolution: can institutional repositories and open access transform scholarly communications?. The ELS Gazette, v. 15, July 2003. Disponível em: < http://www.theelso-gazette.org/magazines/issue/features/features1.asp $>$. Acesso em: 17 ago. 2004.

ROGERS, E. M. Diffusion of innovation. 4. ed. New York: Free Press, 1995.
SUBER, Peter. Removing the barriers to research: an introduction to open access for librarians. College $\mathscr{E}$ Research Libraries News, v. 64, p. 92-94, 2003.

. Open access in the United States. In: JACOBS, N. (Ed.). Open access: key strategic, technical and economic aspects. Oxford: Chandos Publishing, 2006. Disponível em: <http:// eprints.rclis.org/archive/00006671/01/Suber_2006.pdf>. Acesso em: 2006. 